\title{
Unique Traditional Villages on the Loess Plateau of China: Historic Evolution and Challenges to Sustainable Development of Silo-Caves
}

\section{Li Zhang}

Institute of Geography, Henan Academy of Sciences https://orcid.org/0000-0001-6250-9572

Peng Lu ( $\nabla$ bulate_0@163.com )

Institute of Geography, Henan Academy of Sciences https://orcid.org/0000-0002-9336-2697

Lijie Yan

Institute of Geography, Henan Academy of Sciences

Xiang Li

University of Queensland

Ruixia Yang

Laboratory of Digital Earth Sciences: Institute of Remote Sensing and Digital Earth Chinese Academy of Sciences

\section{Panpan Chen}

Institute of Geography, Henan Academy of Sicences

\section{Xia Wang}

Institute of Geography, Henan Academy of Sciences

\section{Research article}

Keywords: traditional village, silo-cave, historic evolution, sustainable development

Posted Date: April 13th, 2021

DOl: https://doi.org/10.21203/rs.3.rs-415252/v1

License: (c) (i) This work is licensed under a Creative Commons Attribution 4.0 International License. Read Full License 


\section{Abstract}

Silo-cave is a unique human habitation form on the Loess Plateau in northern China, which consists of an excavated 6-7 m deep pit as the courtyard and cave dwellings in the surrounding four walls. This architecture has had a history of more than 7000 years, and yet such "living fossils for the history of dwellings" are now facing great crises and challenges during rapid social and economic development. In this paper, remote sensing and GIS techniques are used to comprehensively and systematically investigate the spatial distributions and morphological characteristics of silo-caves at both the macro and micro scales. The research shows that silo-cave villages are mainly distributed in economically underdeveloped areas, such as West Henan (Yuxi), South Shanxi (Jinnan), Central Shaanxi (Guanzhong), and East Gansu (Longdong). The morphological evolution patterns of typical silo-cave villages are identified, including: (1) retaining the periphery and rebuilding the interior, (2) retaining the interior and expanding the periphery, and (3) expanding both the interior and periphery. These patterns are demonstrated to be influenced by many factors, including landforms, traffic conditions, economic development, population growth, and administrative division adjustment. Sustainable development of these traditional silo-cave villages relies on administrative policy and planning, people's awareness of cultural heritage protection, culture inheritance, industrial transformation, and public services.

\section{Introduction}

The silo-cave is a unique dwelling form of human beings, occurring on the Loess Plateau of North China. It features a dwelling unit built by excavating the ground down to create a courtyard and then caves on the four walls of the courtyard (Fig. 1). Known as "the historic village below the horizon and living fossil for the history of dwellings", it is the last surviving earth architecture constructed in accordance with the Rule of Subtraction, and thus a wonder of the human history of dwellings. The silo-cave, a representative of traditional villages with local characteristics, witnesses and preserves occurrence, development, and evolution of the agricultural civilization through thousands of years, and thus is considered highly-valuable in history, architecture, sociology, geology, and art. Over recent years, with improvement in the local living condition, folks move from the underground to the ground. Numerous silo-caves are abandoned and backfilled, or left for collapse. The total quantity rapidly reduces, and it becomes extremely difficult to resee the beauty of such villages. The traditional village based on silo-caves is now facing the danger of loss of settlement features and vanishing of traditional culture. The key to improving the residential environment of local people and facilitating sustainable development of the traditional village is to develop an area-specific development plan, which should, in the first place, protect the traditional village and cultural heritage. The question is HOW.

The silo-cave, as a unique dwelling form, has attracted increasing attention from academia, and studies have been carried out on its construction technique, interior structure, landscape environment, as well as building protection and renovation. Tang et al. [1] summarized the construction process of the silo-cave in the Sanmenxia area, the western Henan Province, and carried out building information modelling of silocaves. Wang and $\mathrm{Li}$ [2] also studied the design and structure of the silo-cave in western Henan, in terms of the construction technique and water drainage. Meng [3] analyzed the settlement pattern of typical silo- 
caves in Dongzhi Tableland. Ye and Zhao [4] discussed the status of landscape protection and utilization of the silo-cave village in Shanzhou. Tian et al. [5] investigated the protection and renovation design of the silo-cave village in western Henan.

At present, research on traditional villages, represented by silo-caves, generally focuses on the regional distribution, architecture feature, and tourism development of such traditional villages [6-19], and macroscopic understanding of the overall framework of the spatial distribution of silo-caves is rarely reported, let alone deep insights at the micro-scale, into the spatial evolution characteristics of typical traditional villages during different periods of time. Quantitative analysis of the geographic characteristics of the spatial geometry and structure of silo-caves has not received sufficient attention. In fact, research on cultural heritage has begun to recognize the importance of the research methodology combining quantitative and qualitative analyses [20-21], of which applications have presented good performance. Especially with the rapid progress and wide application of information technology over recent years, digitalization, quantification, informatization, and visualization have evolved into the inevitable trends of research on cultural heritage. Thus, the study on traditional villages represented by silo-caves also needs to introduce new technologies and methods so as to find a new route for sustainable development, after fully investigating the temporal and spatial distribution and evolution of such historic villages.

This paper studied the traditional silo-cave village in the Yellow River basin. Supported by the spatial information technology, it was feasible to review the historic evolution and overall spatial distribution framework of such a traditional village at the macro scale, and also investigate the characteristics of the spatial geometry and structure of the typical traditional silo-cave village at the micro-scale. This paper attempted to search for a region-specific approach for culturally, ecologically, and economically sustainable development, in order to provide support and help to protection, inheritance, and sustainable development of this unique cultural heritage of humanity.

\section{Research Methodology}

\section{Field investigation}

Deepened field investigation has been carried out for the areas with the concentrated distribution of the traditional silo-cave villages, such as Xizhangcun Town and Zhangbian Town of the Shanzhou District, Sanmenxia City, Henan Province, and Zhangdian Town, Pinglu County, Yuncheng City, Shanxi Province. The historic evolution, quantity change, distribution, landscape characteristic, and challenges in the sustainable development of typical silo-cave villages were investigated and recorded. UAV (unmanned aerial vehicle) aerial photography, multi-view images and videos, and digital measurement were used to elaborately capture the overall distribution and individual morphological features of typical silo-cave villages.

Furthermore, historic and evolution information of these traditional villages was gained from archive review, in-depth interviews, and case studies.

\section{Remote sensing interpretation}


We managed to detailedly investigate the present distribution of the silo-cave villages in the middle reaches of the Yellow River with the help of the Google Earth image, evaluate the status of these silo-cave villages, and interpret the spatial distribution, morphological characteristic, utilization status, and quantity of these silo-cave villages. The spatial distribution of silo-cave villages in the middle reaches of the Yellow River was mapped, and remote sensing imaging of the utilization status of typical silo-cave villages was accomplished.

\section{Building the spatial database}

The multi-source multi-temporal remote sensing images of typical silo-caves and above-ground buildings were vectorized using ArcGIS, respectively, and linked to relevant attribute data, and thus the spatial database for research on typical traditional silo-cave villages was built. Data for the base map of the database were the 1:50000 standard topographic map. Moreover, data of the silo-cave and above-ground building of traditional villages were collected mainly from the remote sensing imaging data and field investigation in areas of interest since 1969; data of economy, population, and other aspects were collected from relevant statistic bulletins and yearbooks. The silo-cave and above-ground building were matched according to the spatial coordinate and basic geographic data, and the spatial position of the settlement was corrected, in order to ensure accuracy and precision of data.

\section{GIS spatial analysis}

The spatial agglomeration characteristic of the internal settlement of silo-cave traditional villages was investigated via kernel density estimation (KDE). This method probes into the distribution characteristic of samples by characterizing the spatial variation of point density of samples across the study area, which can identify and display agglomeration and dispersion of samples across the study area [22-23]. This research measured the spatial agglomeration of settlements within a cross section at different time moments for typical silo-cave villages and presented a visual representation of the distribution patterns.

\section{Results}

\section{Historic evolution}

The history of silo-caves dates back all the way to the early Neolithic Age. Ancient residents living in the loess area and transferring from drifting around to settling down built their homes by caving the loess ground, which was highly adapted to the local condition [24-25]. Such underground cave and semiunderground cave dwellings were found in the Peiliguang ancient cultural relic dating back to 9000-7000 years ago, specifically in both the Egoubeigang relic of Xinmi [26] and the Tanghu relic of Tanghu, Henan [27]. Such dwellings are small in size, with areas generally below $10 \mathrm{~m}^{2}$ and depth below ground level of 0.5-1 $\mathrm{m}$. Without doubt, these underground cave and semi-underground cave dwellings are the embryo form of the later silo-cave, and further demonstrate the time-honored history and environment-adapted tradition of building homes of residents in the loess area by excavating the loess ground 
In the late stage of the Yangshao culture about 5000 years ago, true cave dwellings occurred in the loess area. The oldest cave-dwelling architecture discovered so far is located in the Yanggu relic of the late Yangshao culture, Ning County, Gansu Province [28]. The subsequent Longshan culture (5000-4000 years ago) is seen with increasing cave-dwelling architecture, which gradually evolve into an important dwelling form for early human beings in the loess area. During this process, various styles of cave-dwelling architecture emerged, and the earliest silo-cave architecture came into being-a cave dwelling with a vertically-excavated vestibule. The cave dwelling itself is excavated on the wall of the vestibule. Such cavedwelling remains were found in both the Taosi [29] and Dongxiafeng [30] relics. Later in the Bronze Age (4000-3000 years ago), this form of cave-dwelling architecture became very popular in the loess area [31].

During the Qin and Han dynasties (2000 years ago), the masonry-timber structure gradually replaced the earth-timber structure and emerged as the main house form in China at that time. However, due to the traditional culture and economic limitation of the economy, cave dwellings remained an important dwelling form for residents in the loess area [32]. Cave-dwelling architecture that shared similarities in shapes and structures with the model silo-cave occurred during this period. A U-shaped tomb of the Han dynasty was found in Sanmenxia, and features multiple tomb caves distributed on the three sides of the tomb. The overall tomb structure resembles a complete courtyard, and looks (from above) extremely similar to the modern "silo-cave".

From the late stage of ancient Chinese history to the modern times, silo-caves became the most primary dwelling form in some areas of loess terrace-like plains. This phenomenon continued until the period of reform and opening up of China, after which residents in loess terrace-like plains gradually moved to the ground and lived in above-ground buildings, with the improved economy and change in the concept of dwelling. Moreover, due to the implementation of land reclamation, numerous silo-caves were abandoned and backfilled, which results in the rapidly reduced quantity of silo-caves. People have gradually been reaware of the uniqueness and scarcity of silo-caves since the 1990s. Then, some areas started to protect silo-caves or convert them into tourist sites, which marked a new period for the exploitation of silo-caves (Fig. 2).

\section{Spatial distribution framework}

Remote sensing interpretation reveals that traditional silo-cave villages are mainly located in the terrace-like plain area of the Loess Plateau in North China, featuring thick soil layers and arid climate. The primary concentration of silo-cave villages is found in the Yuxi-Jinnan (West Henan-South Shanxi) and GuanzhongLongdong (Central Shaanxi-East Gansu) areas (Fig. 3). Silo-caves in the Yuxi-Jinnan area are mainly located at the central zones along mountains or the Yellow River, presenting the loess terrace-like plain landform. Specifically, the Yuxi silo-cave is mostly located at the loess terrace-like plain of the eastern margin of the Loess Plateau, such as Gongyi City, Xinan County, Shanzhou District, and Lingbao City. The loess tableland area in the southwestern Shanzhou District, Sanmenxia City owns silo-caves with the largest scale and most concentrated distribution among existing silo-caves in China, mainly in towns such as Zhangbian, Xizhangcun, and Caiyuan. Incomplete statistics show that there are still over 100 belowground traditional villages composed of nearly ten thousand silo-caves. It should be noted that before 1980, 
the silo-cave dwelling is the only dwelling form in the loess tableland area of Shanzhou District. The Jinnan silo-caves are primarily built in the loess terrace-like plain area between the Zhongtiao Mountain and Yellow River, and the main concentration is seen in the towns of the mid-western Pinglu County (e.g. Zhangdian and Changle). As for the silo-caves in the Guanzhong-Longdong area, they are concentrated at the loess terrace-like plain area of the valley of the Jinghe River. Moreover, the Guanzhong silo-caves are mainly distributed in the arid Weibei plain of the transition zone from the Weihe Basin to the Loess Plateau, e.g. the counties such as Changwu, Binzhou, Xunyi, Chunhua, Yongshou, Qianxian, Liquan, and Sanyuan of Xianyang City, Shaanxi Province. On the other hand, Longdong silo-caves accumulate at Dongzhi Tableland in the mid-eastern Qingyang, Gansu Province. From north to south these silo-caves concentrate at Qingcheng County, Heshui County, Qingyang City, and Ningxian County, where they spread outward from the central area of the county across the flat tableland surface. The main concentration is found in Qingyang City and its surrounding areas, followed by the areas along main roads. Areas near the river valley and gully are also seen with numerous silo-caves.

The areas with the concentrated distribution of traditional silo-cave villages are located in the central Loess Plateau and share distinctive regional natural conditions, in terms of the landform, climate, soil, etc. Meanwhile, these areas are all economically underdeveloped and classified as the traditional agricultural regions. Close geographical relationships and consistent cultural settings are found between these areas. Thus notable patterns can be found with respect to the spatial distribution framework of the silo-cave village.

\section{Similar landforms}

The distribution areas of silo-caves all present the landforms of the loess tableland and terrace-like plain of the Loess Plateau, which are mainly characterized by a flat and wide top platform extending downward smoothly and slowly along the hill. The slope of the top platform is mostly of $1-3^{\circ}$ and can reach $5^{\circ}$ at the platform edge. The surrounding of the top platform is cut off by gullies. Due to such landforms featuring localized flatness, ancient residents living there had no cliffs and gully walls to build caves. Therefore, they innovatively constructed cave dwellings penetrating into the underground to create a relatively comfortable, wind-proof, and warm-keeping environment for living. This led to occurences and development of silo-caves in these areas.Fig. 3 Distribution of traditional silo-cave villages in the middle reaches of the Yellow River: (1) Yuxi-Jinnan;( 2) Guanzhong-Longdong

\section{Similar Climates}

The Yuxi-Jinnan and Guanzhong-Longdong areas are both mid-altitude inland areas, and they are featured by the warm temperate continental monsoon climate. The four seasons are distinctive in these areas. Spring is dry and windy; summer is hot and rainy; the temperature drops rapidly in autumn; winter is cold and yet rarely snowy. Rainfall is concentrated in July-September, and the annual average temperature is $9-14^{\circ} \mathrm{C}$. To sum up, the climate there is characterized by hot summer and cold winter, drought, limited rainfall, relatively strong wind with entrained sands, and intensive sunlight. Due to such climate features, people living there try to use the dwelling design to offset the disadvantage of natural conditions-the silocave architecture hides beneath the ground, with the overlying formation to facilitate the indoor environment warm in winter and cool in summer, the advantage of "cave dwelling". The room temperature 
can maintain above $11^{\circ} \mathrm{C}$ in winter and below $20^{\circ} \mathrm{C}$ in summer. Furthermore, the small downward-excavated courtyard of the silo-cave can effectively avoid strong wind and therefore dust, and de-noise, to create an environment applicable to human dwelling and food storage. Clearly, the silo-cave serves as a protective shield between humans and the harsh natural climate condition.

\section{Analogous soil conditions}

These areas are endowed with abundance in loess. The loess deposit is thick, with a thickness generally of 20-250 m. Loess there are deposited during the early, middle, and late Pleistocene. The loess layer is rigid, tight, and commonly developed with vertical joints (therefore high capacity to maintain the standing posture and less prone to collapse). It is resistant to vertical loading, earthquake, and alkaline corrosion. Moreover, the arid climate there is in favor of soils to keep dry and rigid, which improves the service life of cave-dwelling architecture. The natural conditions of areas with concentrated distributions of silo-caves are summarized in Table 1.

Table 1

Natural conditions of areas with concentrated distributions of silo-caves

\begin{tabular}{|c|c|c|c|c|c|c|}
\hline Area & Landform & $\begin{array}{l}\text { Elevation } \\
\text { / m }\end{array}$ & Climate & $\begin{array}{l}\text { Annual } \\
\text { Average } \\
\text { Precipitation } \\
\text { / mm }\end{array}$ & $\begin{array}{l}\text { Annual } \\
\text { Temperature } \\
/{ }^{\circ} \mathrm{C}\end{array}$ & $\begin{array}{l}\text { Soil } \\
\text { Thickness } \\
\text { / m }\end{array}$ \\
\hline Yuxi & $\begin{array}{l}\text { Loess terrace- } \\
\text { like plain at } \\
\text { the eastern } \\
\text { margin of the } \\
\text { Loess Plateau }\end{array}$ & $500-800$ & $\begin{array}{l}\text { Warm } \\
\text { temperature } \\
\text { monsoon } \\
\text { climate }\end{array}$ & $550-680$ & 13.6 & $20-70$ \\
\hline Jinnan & $\begin{array}{l}\text { Loess terrace- } \\
\text { like plain } \\
\text { between the } \\
\text { Zhongtiao } \\
\text { Mountain and } \\
\text { Yellow River }\end{array}$ & $500-700$ & $\begin{array}{l}\text { Warm } \\
\text { temperature } \\
\text { monsoon } \\
\text { climate }\end{array}$ & $500-620$ & 13.8 & $40-50$ \\
\hline Guanzhong & $\begin{array}{l}\text { Loess terrace- } \\
\text { like plain of } \\
\text { Guanzhong }\end{array}$ & $400-600$ & $\begin{array}{l}\text { Warm } \\
\text { temperature } \\
\text { monsoon } \\
\text { climate }\end{array}$ & $600-700$ & 13.3 & $80-100$ \\
\hline Longdong & $\begin{array}{l}\text { Loess terrace- } \\
\text { like plain of } \\
\text { the Shan-Gan- } \\
\text { Ning Basin } \\
\text { (Dongzhiyuan) }\end{array}$ & $\begin{array}{l}1250- \\
1400\end{array}$ & $\begin{array}{l}\text { Warm } \\
\text { temperature } \\
\text { monsoon } \\
\text { climate }\end{array}$ & $480-550$ & 9.1 & $150-250$ \\
\hline
\end{tabular}

\section{Homogeneous economic levels and structures}

The silo-cave concentration areas are all economically-underdeveloped areas of Middle and West China. In these areas, the backward economy suffers from an inferior economic foundation. The regional economy is 
mainly based on conventional agriculture, which leads to a simple economic structure. Taking Shanzhou District in the Yuxi area, Pinglu County in Jinnan, Chunhua County in Guanzhong, and Qingcheng County in Longdong as examples, the per capita gross domestic production (GDP) and rural per capita disposable income in 1978, 2008, and 2018 are all below the national average levels (Table 2 and Fig. 4). In the early stage, these areas are commonly seen with a lack of construction materials to build dwellings, and people living in such wide plains with insufficient natural barriers and construction materials have to seek shelter in the underground space. Therefore, the choice is made to excavate the ground and build homes, which gradually evolves into a dwelling habit during the prolonged history that continues up to now.

Table 2

Economic levels of areas of traditional silo-cave villages in 1978-2018

\begin{tabular}{|lllllll|}
\hline Term & \multicolumn{3}{l}{$\begin{array}{l}\text { Per Capita GDP } \\
\text { Area }\end{array}$} & \multicolumn{5}{l}{$\begin{array}{l}\text { Rural Per Capita Disposable Income } \\
\text { / RMB Yuan }\end{array}$} & \multicolumn{3}{c|}{ / RMB Yuan } \\
\cline { 2 - 8 } & $\mathbf{1 9 7 8}$ & $\mathbf{2 0 0 8}$ & $\mathbf{2 0 1 8}$ & $\mathbf{1 9 7 8}$ & $\mathbf{2 0 0 8}$ & $\mathbf{2 0 1 8}$ \\
\hline Shanzhou, Henan & 324 & 18484 & 45855 & 126 & 4192 & 12916 \\
\hline Pinglu, Shanxi & 211 & 5986 & 18164 & 101 & 2777 & 7776 \\
\hline Chunhua, Shaanxi & 265 & 10438 & 35689 & 119 & 2946 & 9721 \\
\hline Qingcheng, Gansu & 245 & 11973 & 38952 & 102 & 2696 & 8595 \\
\hline Nation-wide average & 381 & 22698 & 64644 & 134 & 4761 & 14617 \\
\hline
\end{tabular}

\section{Consistent cultural settings}

The Chinese Civilization originated from the hinterland in the middle reaches of the Yellow River, which, as the source of the ancient civilization of the Yellow River valley, provides a consistent cultural setting for people across the area. Due to the close geographic relationship and consistent cultural setting, people living in the silo-cave concentration areas have similar dwelling forms and habits. Discoveries in base sites of numerous relics of the Yangshao culture in these areas, such as the Miaodigou relic in Shanzhou District, Beishouling relic in Baoji, Jiangzhai relic in Lintong, Banpo relic in Xi'an, Xiwangcun relic in Ruicheng of Shanxi, have shown that the village dwellings in this historic period are dominated by semi-underground caves. Owing to the dry climate and thick soil layers of the Loess Plateau, ease in excavation, and the advantage in the lee of keeping warm and effectively avoiding winds (and entrained sands), cave dwelling and semi-cave dwelling architecture extensively occurred and developed in these areas. As time passed by, cave dwellings evolved from horizontal caves, to bag-like vertical caves, then semi-cave dwellings, and at last the present silo-cave architecture. Clearly, the consistent cultural setting contributes to the occurrence, development, and inheritance of traditional silo-cave villages in the areas mentioned above.

\section{Morphological evolution characteristics of typical villages}


By analyzing the morphological evolution of typical silo-cave villages since 1980 , such as Houguan and Miaoshang Villages of Xizhangcun Town, and Qucun Village of Zhangbian Town in Shanzhou District, this paper managed to identify three patterns of morphological evolution of traditional silo-cave villages, namely retaining the periphery and rebuilding the interior, retaining the interior and expanding the periphery, and expanding both the periphery and interior.

(1) Retaining the periphery and rebuilding the interior

Houguan Village is located in Xizhangcun Town, Shanzhou District, with the Dalei line of the provincial highway S245 penetrating the center of the village. Before 1980, villagers mostly lived in silo-caves. Since 2000 , above-ground dwellings were built mainly along the provincial highway $\mathbf{2} 245$. By 2018, more aboveground buildings have been placed inside the village along the main traffic roads, which leaves only the periphery of the village retaining some traditional silo-cave architecture (Fig. 5). The silo-cave settlement morphology of the whole village presents the unchanged periphery and rebuilt interior, in which the traditional silo-cave villages are abandoned and newly-built above-ground buildings are placed along main roads inside the original village. Factors contributing to such evolution of traditional villages include traffic, administrative policy, and self-agency of villagers, among which variation of traffic conditions and resultant guiding effects are the main contributors.

(2) Retaining the interior and expanding the periphery

Miaoshang Village is located in Xizhangcun Town, Shanzhou District, Henan Province. The remote sensing imaging in 1980, 2000, and 2018 reveals a pattern of retaining the interior and expanding the periphery, in terms of the morphological evolution of the whole village (Fig. 6). With this pattern, the traditional silo-cave village is generally well preserved, and new buildings for the village are built in the periphery of the original village in a well-planned manner. Factors leading to this pattern of traditional village evolution are the administrative policy, planning guidance, and self-agency of villagers, among which the administrative policy and planning have significant impacts upon the morphological evolution of villages.

(3) Expanding both the periphery and interior of the village

Qucun Village is located in Zhangbian Town, also Shanzhou District, Henan. It is seen in the remote sensing imaging of 1980, 2000, and 2018 that the morphological evolution of the whole village is characterized by the expansion of both the interior and periphery of the village. Newly-built above-ground buildings are randomly placed both in the interior and on the periphery of the original village (Fig. 7). In this evolution pattern, the traditional silo-cave village is generally found with the simultaneous hollowing and periphery expansion, and the style and spatial texture of the previous traditional silo-cave village are compromised. Factors affecting this traditional village evolution pattern are mainly the self-agency of villagers, traffic infrastructure, and government guidance, among which lack or delaying of administrative policy and planning is the major contributor.

\section{Evolution regularity of internal structures of typical traditional villages}


Here Qucun is further analyzed to demonstrate the spatial structure evolution characteristics of internal structures (including both silo-caves and above-ground buildings) of the village at different time moments. Two time moments, namely 1969 and 2018, are chosen for analysis.

Qucun, a typical traditional silo-cave village, features a landform of the typical loess tableland at the eastern margin of the Loess Plateau. In September 2016, Qucun was included in the 4th List of Traditional Villages of Henan Province. In 2018, the total village area of Qucun reaches 287 hectares, among which 40.75 hectares are of village construction; 152.67 hectares, of farming; 66.54 hectares, of woods; 27.04 hectares, of other usages. There are now ten villager groups in Qucun, including a total of 435 households for a total population of 1527 .

Remote sensing interpretation illustrates 172 silo-cave settlements across the village in 1969 (Fig. 8a). Over recent years, the quantity of silo-caves in Qucun gradually declines. According to field survey and document review, there were 130 silo-cave settlements in Qucun in 2018, presenting a reduction by 42 from 1969. The existing silo-caves were mostly built before 1949 , among which two were built in the Ming dynasty; 32 , in the Qing dynasty; 49, during the period of the Republic of China. Forty-seven silo-caves were built after 1949. Among the existing silo-caves, 74 (57\% of the total) are well preserved, with structural integrity and retained style and features. Twenty-one silo-caves ( $16 \%$ of the total) are seen with slight inferior preservation, with partial structures and decorative elements damaged. The rest 35 silo-caves $(27 \%$ of the total) are found with remaining overall structures and yet collapse of caves on one or more sides of the courtyard. Moreover, numerous above-ground dwellings have been built (Fig. 8c), including a total of 20 households with brick houses, mostly constructed before 2010, and 110 households with storied and onestory houses, mostly built after 2010. The silo-caves and above-ground architectures are arranged in a chaotic manner, which damages the morphology and texture of the original village. The building distribution inside the traditional silo-cave village is vectorized via interpretation and digitization of the remote sensing image (Figs. $8 \mathrm{~b}$ and $8 \mathrm{~d}$ ).

Then, with the Density tool in the ToolBox of ArcGIS 10.1, the kernel density analysis has been carried out on the settlements of Qucun in 1969 and 2018 (Fig. 9). By doing so, agglomeration of traditional in this traditional village was investigated at the micro-scale, which mainly produces the following findings:

(1) There are mainly four agglomeration zones of silo-caves in Qucun, located in the northeastern, northern, central, and southwestern parts of the village, respectively (Fig. 9a).

(2) Compared with 1969, 2018 presents a huge reduction of the silo-cave quantity, mostly occurring in the central and southern parts of the village. The existing silo-caves are concentrated in three zones, located in the northeastern, northern, and southwestern parts of the village (Fig. 9b).

(3) Distribution of newly-built above-ground architectures is less organized. Such architecture is randomly placed inside the village, and the two zones with relative concentrations of them are in the northwestern and southeastern parts of the village (Fig. 9c). 
Based on analysis of the morphological evolution characteristics and variation of settlement agglomeration of Qucun, a typical traditional silo-cave village, we managed to carry out further function division of this traditional village, in accordance with the consistency of the overall village landscape spatial texture. The key protection zone for silo-caves is demarcated, and some modern above-ground buildings that are inconsistent with the traditional style and features of the village are removed or relocated, which provides technical support to developing the concept of renovating the internal structure of the traditional silo-cave structure (Fig. 10).

\section{Discussion}

\section{Crises and challenges}

Before 1980, the silo-cave dwelling is basically the only dwelling form in the loess tableland area. With the implementation of the reform and opening-up policy in China and the resultant rapid growth of society and economy, the traditional silo-cave village is facing many problems, such as rapid reduction of quantity, damage of settlement textures, loss of traditional culture, insufficiency of infrastructure, and deterioration of living environments. Reasons behind these problems include: First, due to impacts of the market-oriented economy and change of people's conception for dwelling, more and more people move from the underground to the ground. Moreover, the silo-cave is characterized by a large floor area (typically the floor area of a silo-cave is 1-1.5 Chinese mu, which is three-five times that of the present homestead). In the middle 1990s, the policy of returning house land to farmland was implemented, and numerous silo-caves were backfilled or abandoned and left for collapse, which led to rapid reduction of the silo-cave quantity and shrinking of the silo-cave area. Such phenomena evolved into a common tendency in all silo-cave distribution areas such as Yuxi, Jinnan, Guanzhong, and Longdong. Second, the development of the traditional silo-cave village is seen with insufficient scientific planning and no clear function division, and the arrangement of ever-increasing above-ground buildings is not well organized, which damages the unified spatial texture of the traditional silo-cave village and results in high difficulties in maintaining the style and features of the silo-cave village. Third, the construction technique of traditional silo-caves had rare practicers, and such an intangible cultural heritage fails to be inherited, which accelerates the vanishing of the silo-cave architecture culture. Fourth, the overall infrastructure facility of the traditional village is inferior, and the dwelling condition thus gradually deteriorates.

\section{Development and opportunities}

The aforementioned problems result in severe crises and challenges for the protection and sustainable development of traditional silo-cave villages. However, it should be noted that over recent years, with proposal and implementation of the rural revitalization, development of the ecological civilization, and highquality development strategy, protection, and utilization of such traditional villages with distinctive regional features and values of multiple aspects have entered a new stage, from perspectives of both the government policy and public awareness. Increasing local governments or individuals commit to protection or development as tourist sites of silo-caves. For instance, in Shanzhou District, multiple traditional silocave villages such as Miaoshang and Renmazhai Villages of Xizhuangcun Town, and Beiying, Qucun, and 
Liusi Villages of Zhangbian Town have been included in the List of Traditional Villages of China (or Henan Province). According to consistent planning criteria, Beiying Village restored over 80 silo-caves, which was developed into the Shanzhou Silo-cave tourist attraction and presented the historic evolution of silo-caves as well as the lifestyle and folkway of people living in the Yellow River basin to the audience in an allaround manner. In 2016, this tourist attraction is awarded the Scenic Area with the Most Potential by the China "Internet +" Summit, and considered a success of "Internet + Tourism". Also, Baishe Village of Sanyuan County and Lijiahougou Village of Qingcheng County in the Guanzhong-Longdong area made valuable attempts in protection and tourism development of traditional villages, which produce a great outcome. Nonetheless, generally speaking, the development and construction of traditional silo-cave villages in each area still present some characteristics of self-organization and self-motivation. Redevelopment and utilization of traditional silo-cave villages are now in lack of guidance of the systematic and region-specific sustainable development theory. Given this, it is extremely urgent to propose a highly region-specific approach for the sustainable development of traditional silo-cave villages, in terms of policy development and guidance, architecture protection and renovation, culture exploitation and inheritance, industry development and transformation, and utilization and public service, based on the natural conditions and fundamental characteristics of the ecological environment in the middle reaches of the Yellow River.

\section{Path selection of sustainable development Guidance of government policy and planning}

The guidance provided by the government policy and planning plays an increasingly important role in the sustainable development of traditional villages. Given the status of traditional silo-cave villages and problems encountered during development, the government and the implementation departments of planning shall scientifically plan and develop corresponding policy in a case-specific manner. For example, during the planning of such traditional villages, the work shall be based on the current natural environment of the village and aim at protecting the integrity of the silo-cave village. Meanwhile, the plan shall as much as possible protect and preserve the authenticity and uniqueness of the historic information contained by the traditional silo-cave village. Only by doing so can the unique value and distinctive regional style and feature of such traditional silo-cave villages be sufficiently and completely presented.

\section{Protection and renovation of silo-caves}

Maintaining integrity and rationality of the settlement morphology is the premise for sustainable development of traditional villages. Given the existing problems and disadvantages of current silo-cave architecture, protection and renovation of such structures shall be improved, with respect to the creation of settlement features, the manifestation of styles, and the enhancement of physical environments. The creation of the overall feature of settlements shall sufficiently match the landform so as to constitute ordered and unified village textures. Design of individual buildings shall pay attention to conformity with the overall environment, and also improving the visual rendering and representation of regional characteristics via elements such as colors, sizes, and decoration. Moreover, appropriate technical measures shall be taken to enhance the lighting and ventilation performances of silo-caves. All these 
efforts are made to make silo-caves more adapted to people's new lifestyles and living demands, and revitalize traditional silo-cave villages via protection and renovation of architectures.

\section{Mining and inheritance of regional culture}

The traditional silo-cave village is a distinctive settlement form of the Yellow River basin, and its endowed historic context represents the regional history. Mining and inheritance of the regional culture contained in the traditional silo-cave village are of great importance, as they resemble the development and continuation of the local cultural context. By taking full advantage of the shared setting of the Yellow River basin, which serves as a bond, one is able to deeply combine the traditional silo-cave village with the geographical, cultural, and inhabitant characteristics. With the help of new spatial information technologies and methods, the historic cultural context and structural features of such distinctive regional villages can be interpreted in a proper manner from multiple disciplines such as geography, architecture, archaeology, and sociology. By doing so, one is able to identify harmony and localism of the lifestyle of local people, extract the value contained by the Yellow River culture for the current time, highlight the regional historic and cultural features, build the cultural brand of the Yellow River basin, and preserve and promote the Yellow River culture, so as to inject new charms and vitality into the traditional silo-cave village.

\section{Industry development and transformation}

Sustainable development of traditional villages is an organic updating process, which needs a continual injection of power to sustain progress. Support of local industries cannot only inject fresh vitality for the development of traditional villages but also stimulate the vitality of local culture. Therefore, industry development and transformation are critical to the protection and development of traditional silo-cave villages. For different types of traditional silo-cave villages, the industry pattern is required to be designed as suitable as possible to the time and environment, according to the actual situation, for industry selection and development orientation. For instance, the traditional village focusing on tourism development shall highlight its authenticity. Protection and inheritance of the regional culture shall be emphasized, and the main efforts shall be made to improve the local culture-tourism-integrated development. Tourism development shall sufficiently reflect the connotation of the regional culture, demonstrate the characteristics of the Yellow River culture, and attract tourists with unique folkways and high-quality products and services, in order to make the silo-cave a real national cultural tourist attraction.

\section{Allocation of lands and public services}

Proper allocation of land resources, improvement in public services, and integration of public space are in favor of enhancing the sense of identity and belonging of residents in traditional silo-cave villages. For example, efforts can be made to create public space around big old trees or in the front entrance of the village or create space for entertaining and relaxing activities by protecting and improving original public space (restoring old buildings and enhancing the street space) to provide room for people's social interaction. Fulfilling various demands of residents in terms of the residential environment and stimulating spiritual and physical exchange and interaction among local residents can enhance cohesion and sense of belonging of people living in the traditional silo-cave village. 


\section{Conclusions}

Through the analysis presented above, the following conclusions are drawn.

(1) Distribution of silo-caves follows consistency in natural conditions.

In general, the spatial distribution of silo-caves presents outstanding regularity, and the concentration areas of traditional silo-cave villages are all located in central Loess Plateau, sharing consistent natural conditions of landforms, soils, and climate. The landforms are all the loess tableland and terrace-like plain of the Loess Plateau. The top platform surface is flat and wide, with thick soil layers that are rigid, tight, and less prone to collapse due to the development of vertical joints and resultant capacity to maintain an erection. Loess is characterized by its resistance to vertical loading, earthquake, and alkaline corrosion. The climate is all warm temperature monsoon climate, with distinctive four seasons. The areas are dry with limited rainfall and relatively strong winds (with entrained sands). Moreover, these areas are economically underdeveloped and all classified as the conventional agricultural region. With such natural conditions, people choose to build homes by excavating the ground in place to live. This construction technique of homes can lower the living cost by using local materials and also achieve the purposes of keeping warm and protecting people from winds and entrained sands. Also, these areas share close geographical relationship and consistent cultural setting. The aforementioned factors lead to the occurrence, development, and inheritance of traditional silo-cave villages in the Yuxi, Jinnan, Guanzhong, and Longdong areas.

(2) Evolution of silo-cave villages represents the human-land interaction process, in which humans learn about, exploit and modify nature.

If we regard the traditional silo-cave village as the regional system of harmony between nature and man, resulting from the overall coordination among the human society and economy and the natural surrounding, the competing process of co-existing traditional silo-caves and newly-built above-ground buildings inside traditional villages manifests evolution of the village morphology and structure. By investigating the evolution characteristics and patterns of the spatial morphology and structure of typical silo-cave villages, three evolution patterns for the morphology of traditional villages are identified, namely retaining the periphery and rebuilding the interior, retaining the interior and expanding the periphery, and expanding both the interior and periphery. Moreover, control factors for different evolution patterns include the landform, traffic infrastructure, administrative policy and planning, self-agency of villagers, and adjustment of administrative division. The evolution of villages represents a highly regional human-land interaction process, and the status of evolution is the inevitable result of the specific current settings of society, economy, technology, and culture.

(3) Traditional silo-cave villages shall find region-specific development paths in accordance with the characteristics of the regional environment.

The traditional silo-cave village, known as the living fossil for the history of local-style dwellings, is facing severe crises and challenges in the current rapid development process of society and economy. Re-

Page 14/ 23 
development and utilization of such unique traditional villages require well considering the background factors of the regional natural and social environments and searching for development approaches and formats that are applicable to the local conditions, after classifying development modes of traditional silocave villages. Efforts shall be made to improve the guidance provided by government policy and planning, enhance protection and renovation of traditional architectures, facilitate mining and inheritance of regional culture, develop time- and environment-appropriate industry pattern design, properly allocate land resources, and optimize public services, in order to find a region-specific path for sustainable development of traditional silo-cave villages.

(4) Inter-discipline multi-angle systematic analysis becomes an important topic for research on sustainable development of traditional villages.

This research combines modern digitalization technology and conventional qualitative research. Based on field surveys, this study comprehensively and systematically investigates the spatial distribution and morphological characteristics of silo-caves at both the macro and micro scales, using remote sensing and GIS techniques. The natural, social, and economic factors affecting village evolution and also the evolution mechanisms are analyzed from multiple angles, and the coupling system of the influential factor and sustainable development has been built in an attempt to achieve systematic deconstruction and quantitative characterization. The proposed research approach provides not only the innovation of methodology for studying traditional villages but also the foundation for digitalization-assisted protection and sustainable development of traditional villages. It enables dynamic surveillance of protection and development of traditional villages, based on which people are able to find the region-specific path for culturally, ecologically, and economically sustainable development of traditional villages. This is an important aspect to promote sustainable development and protection of such traditional villages.

To sum up, there are multiple factors behind the differentiation of the spatial structure, architecture form, constitutive element, construction technique, and color of traditional silo-cave villages from other traditional local-style settlements, and consequently the outstanding regional characteristics. In other words, the occurrences and development of silo-caves are closely correlated to the local natural environment, social culture, lifestyles, and customs. Silo-caves continue to evolve under the effects of the above factors and finally form their unique settlement characteristics, which also manifests the common regularity of survival and development of local residents (adapting to the environment). Such traditional villages known as living fossils for the history of dwellings are now found facing extreme crises and challenges during the current rapid development of society and development. This research only addresses the historic evolution, the overall framework of temporal-spatial distribution, and the internal evolution characteristics of the traditional silo-cave village. Therefore, it lacks in-depth investigation of factors affecting the morphology and structure of the traditional village as well as the differentiation of traditional silo-cave villages in different areas. The evolution mechanism of traditional villages can be well interpreted by doing research that integrates influential factors and differentiation characteristics of the spatial morphology and structure of traditional villages and thus builds the protection system featuring correlated typical features and carriers of protection elements. In this way, it also creates a huge research space for developing a regionspecific path for the sustainable development of traditional silo-cave villages. 


\section{Declarations}

Author Contributions: Data curation, Lijie Yan; formal analysis, Peng Lu and Ruixia Yang;validation, Xiang Li and Xia Wang; visualization, Panpan Chen;writing-review and editing, Li Zhang. All authors have read and agreed to the published version of the manuscript.

Funding: This research was funded by the National Natural Science Foundation of China (Grant Nos. 41701014,41971016 and 41671014 ), the National Social Science Foundation of China (Grant Nos.18CKG003 and 19ZDA227), Soft Science Research Project of Henan Province (Grant No. 192400410067),Science and Technology Project of Henan Province (Grant No. 192102310019), the Study of Environment archaeology in Zhengzhou, the Digital Environment Archaeology Specially-appointed Researcher of Henan, China (Grant No. 210501002), the basic scientific research of Henan (Grant No. 210601027), and the Research on the Roots of Chinese Civilization of Zhengzhou University (XKZDJC202006), and the Science and Technology Think-Tank Project of Henan Academy of Sciences (Grant No. 210701002).

Data and materials Availability Statement: The data presented in this study are available on request from the corresponding author. The data and materials are not publicly available due to privacy reasons.

Competing Interest:The authors declare no conflict of interest.

\section{Author details:}

Li Zhang, Peng Lu, Lijie Yan, Panpan Chen, Xia Wang冈Institute of Geography, Henan Academy of Sciences, Zhengzhou 450052, China 『Zhengzhou Base, International Center on Space Technologies for Natural and Cultural Heritage under the auspices of UNESCO, Zhengzhou 450052, China『dlszhangli@163.com(L.Z.); bulate_0@163.com (P.L.); lijiey1213@sina.com (L.Y.); cppbed@163.com (P.C.); 15600624913@163.com (X.W.)

Xiang Li,School of Earth and Environmental Sciences, University of Queensland, Brisbane, QLD4072, Australia『xiang.li11@uqconnect.edu.au

Ruixia Yang $₫$ Key Laboratory of Digital Earth Science,Institute of Remote Sensing and Digital Earth, Chinese Academy of Sciences, No.9, Dengzhuang South Road, Haidi, Beijing 100094, China 『yangrx@radi.ac.cn

\section{References}

1. Li Tang XZ. Traditional House "Underground Courtyard" $\bigotimes$ The Construction of Pit Courtyard: Take Fan Village of Shan County as an Example. Huazhong Architecture. 2011;29(3):3.

2. Guixiu Wang HL. Analysis on Structure of Waterproof and Drainage Systems of Pit House in the West of He'nan Province. Construction Technology. 2013;42(16):4.

3. Meng Y. Dong Zhi Tableland Typical Pit Settlement Research: Xi'an University of Architecture and Technology; 2013. 
4. Tong Ye MZ. Analysis on Structure of Waterproof and Drainage Systems of Pit House in the West of He'nan Province. Chinese and Overseas Architecture. 2018(7):3.

5. Pengpeng Tian EL, Yushang Huang, Ying Xiang. Study on the Protection and Renewal Design of Pit House Villages in Western HenanषA Case Study of Qu Village in Shan County. Journal of Hunan University of Technology. 2018;32(2):8.

6. Qi J. The Regional Differentiation and Formation Mechanism of Traditional Residential Landscape in Shaanxi. Journal of Arid Land Resources and Environment. 2016;30(4):6.

7. Man Li LC, Ge Sun, Yuhui Lv. The Rebirth of the Rural Settlements-Demonstration of Pit Cave-dwellings Renovation in Baishe Village, Sanyuan County, Shaanxi Province. Architecture \& Culture. 2017(12):5.

8. Liu P. Composition Symbol of Traditional Chinese Village Image. Journal of Hengyang Normal University. 1994(4):6.

9. Wang X. Practice and Thinking on the Value Identification and Overall Protection of Traditional Villages. Journal of Southwest Minzu University (Humanities and Social Science). 2013(2):5.

10. Yuncai Wang HG, Li Yang. The Discussion on Evaluation and Sustainable Development Models of Traditional Villages in Western Mountainous Area of Beijing -A Case Study of Traditional Villages in Mentougou District of Beijing. Scientia Geographica Sinica. 2006;26(6):8.

11. Haifan Cheng NL, Zhirui Mao. A Preliminary Study on the Dynamic Mechanism of the Renewal of Traditional Villages--Based on the current tourism development background. Architectural Journal. 2011(9):4.

12. Zhenyu Che JB. Research on Tourism Development of Traditional Villages and the Change of Form. Planners. 2006;22(6):16.

13. Jianzhong Zhang JL, Da Chai. Ancient Village Tourism Development Based on Cultural and Ecological Perspective -Taking Ancient Hougou Village as an Example. Economic Geography. 2015;35(9):6.

14. Tong Y. Research on the Spatial Differentiation of Chinese Traditional Village Based on GIS. Human Geography. 2014;29(4):8.

15. Zhongmei Guan TW, Xiaoxiao Zhi. Temporal-Spatial pattern Differentiation of Traditional Villages in Central Plains Economic Region. Economic Geography. 2017;37(9):8.

16. Hui Zhang JC, Shaoying Xiao, Jingjing Liu, Xiaochao Yue. Research on Temporal and Spatial Distribution and Evolution Characteristics of Traditional Villages in Taihang Mountain. City Planning Review. 2020;44(8):8.

17. Bohua Li SY, Peilin Liu, Yindi Dou. Spatial Distribution of Traditional Villages and the Influencing Factors in Hunan Province. Economic Geography. 2015;35(2):6.

18. Wei Tao HC, Jieyong Lin. Spatial form and spatial cognition of traditional village in syntactical view: A case study of Xiaozhou Village, Guangzhou. Acta Geographica Sinica. 2013;68(2):10.

19. Gegentana LD, Tinghua Hu, Xiaoqing Hu, Yuanjing Yin, Ying Meng. Study on the Spatial Characteristics of Religious Traditional Villages-Take Songpan County, for Example. Open Journal of Social Sciences. 2020;8(4):11. 
20. Zongxing Chen XC. Geographical Researches on Rural Settlements: Review and Prospect. World Regional Studies. 1994(1):8.

21. Yuill RS. The Standard Deviational Ellipse; An Updated Tool for Spatial Description. Geografiska Annaler: Series B, Human Geography. 2017;53(1):12.

22. Xu Z. Ten Lectures on Pre-Qin History: Zhonghua Book Company; 2009.

23. Chen L. Mr Xu Zhongshu and His Research on Xia and Shang history. Yindu Journal. 2002(3):4.

24. Henan Working Team No.1 of IA C. Excavation of the Neolithic Site at Peiligang. Acta Archaeologica Sinica. 1984(1):40.

25. Songlin Zhang YX, Yayi Hu, Fuhai Yan. A Brief Report on the Excavation of the Peiligang Cultural Remains at the Tanghu Site in Xinzheng, Henan. Archeology. 2008(5):19.

26. Junchen Xu HL. Brief Report on Trial Excavation of Yangwa Site in Ningxian County, Gansu Province. Archeology. 1983(10):8.

27. Guo-feng Wei CZ, Guo-liang Chen, Yu-ling He, Jiang-tao Gao, Bing-jian Zhang. Study on Archaeological Lime Powders from Taosi and Yinxu Sites by FTIR. Guang pu xue yu guang pu fen xi = Guang pu. 2015;35(3):6.

28. Tian J. Analysis and Significance of Remains of Dongxiafeng in the Late Longshan Period. Sanjin Archaeology. 1996;2:6.

29. Wang T. The Study of pre Qin Cave Dwelling In the Loess Plateau: Northwest University; 2017.

30. Qian Y. The Emergence of Cave-dwelling Buildings and Their Environmental Archaeological Significance. Cultural Relics. 2004(3):9.

31. Committee SCLHAC. Tha Annals of Shan County: Henan People 's Publishing House; 1988.

32. Zhao F. A Preliminary Study on the Construction Technique for Cave dwellings in Pinglu County: Shanxi University; 2015.

\section{Figures}



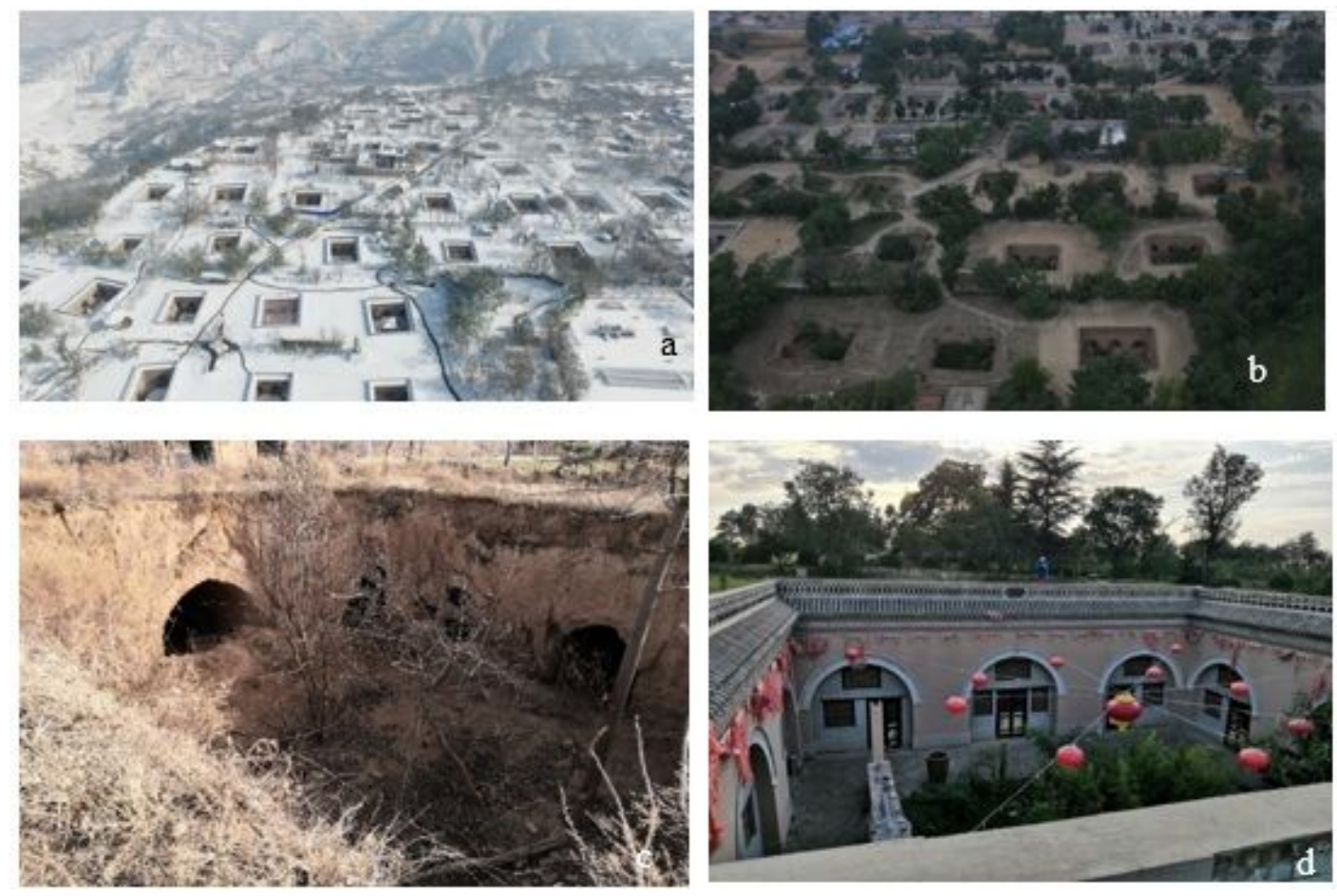

Figure 1

The present traditional silo-cave villages $₫$ (a) the aerial view of Beiying Village, Zhangbian Town, Shanzhou District; (b) the aerial view of Qucun Village, Zhangbian Town, Shanzhou District; (c) the abandoned silocave of Zhangbian Village, Zhangbian Town, Shanzhou District; (d)the renovated silo-cave of Qucun Village, Zhangbian Town, Shanzhou District. Note: The designations employed and the presentation of the material on this map do not imply the expression of any opinion whatsoever on the part of Research Square concerning the legal status of any country, territory, city or area or of its authorities, or concerning the delimitation of its frontiers or boundaries. This map has been provided by the authors.

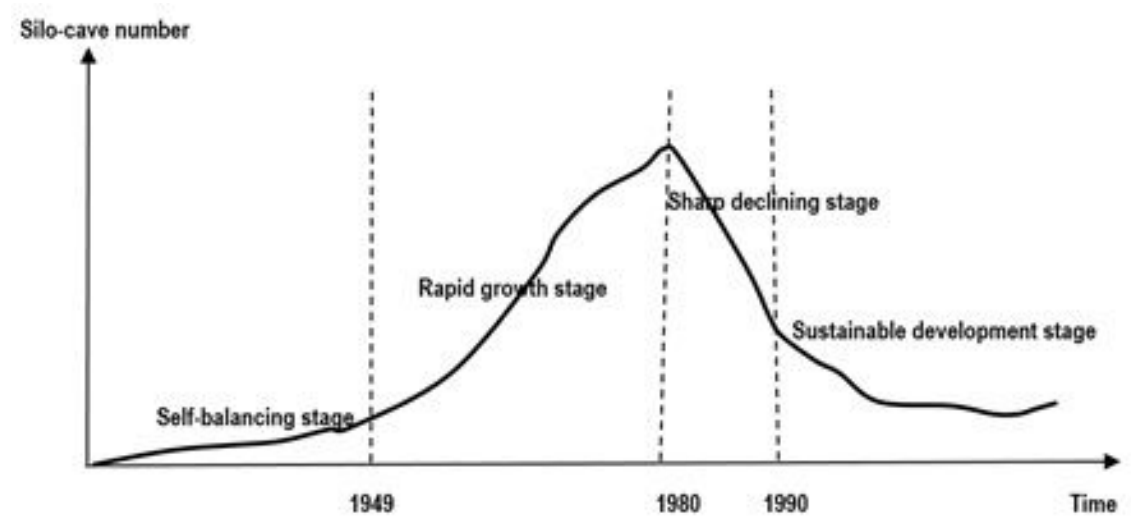

Figure 2

Evolution stages of silo-caves 


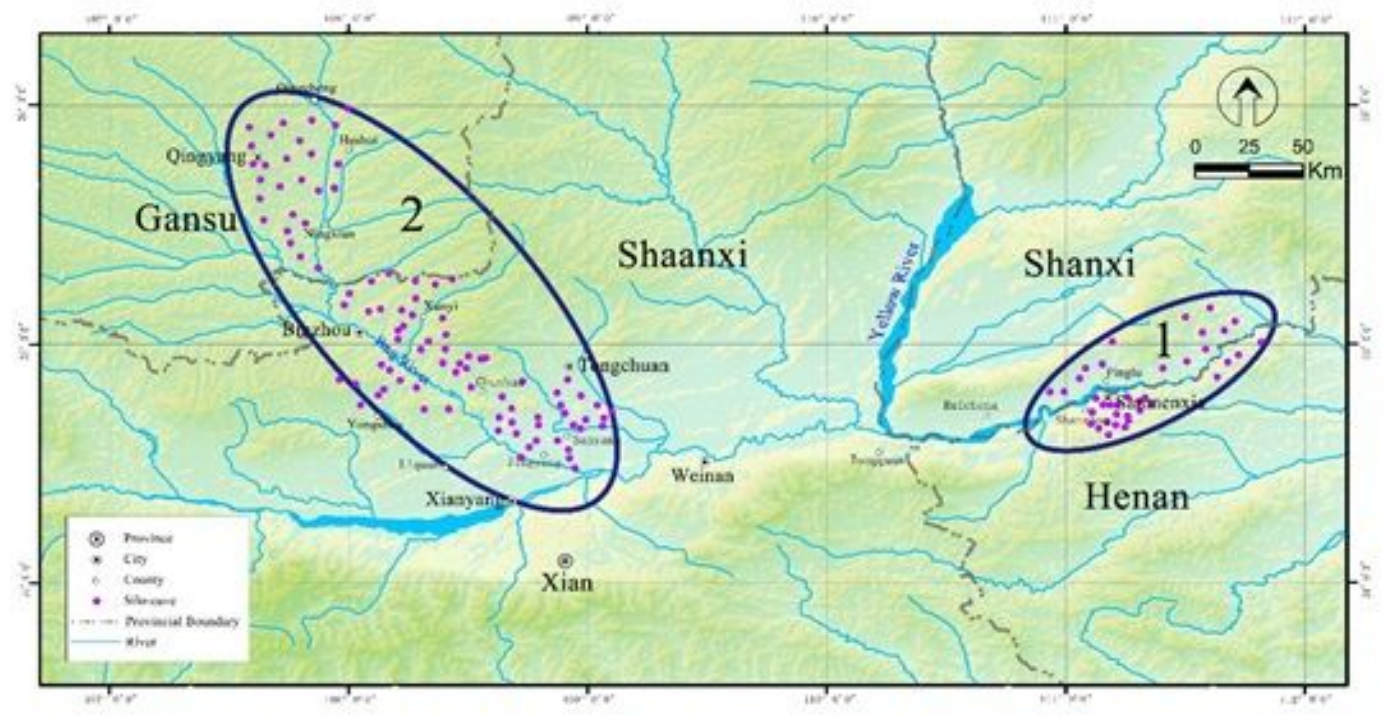

\section{Figure 3}

Distribution of traditional silo-cave villages in the middle reaches of the Yellow River: (1) Yuxi-Jinnan;( 2) Guanzhong-Longdong. Note: The designations employed and the presentation of the material on this map do not imply the expression of any opinion whatsoever on the part of Research Square concerning the legal status of any country, territory, city or area or of its authorities, or concerning the delimitation of its frontiers or boundaries. This map has been provided by the authors.
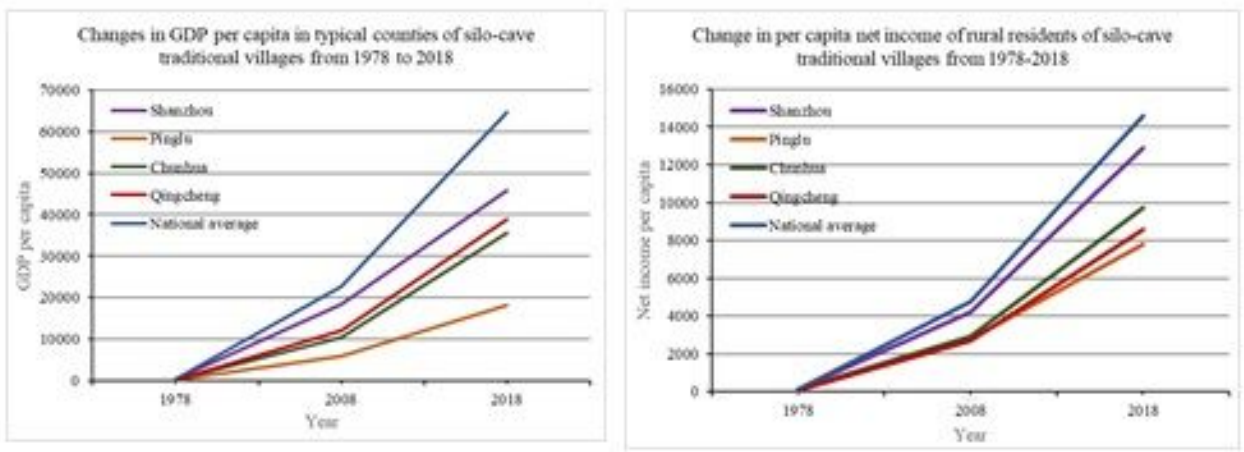

\section{Figure 4}

Economic comparison of typical areas with traditional silo-cave villages 

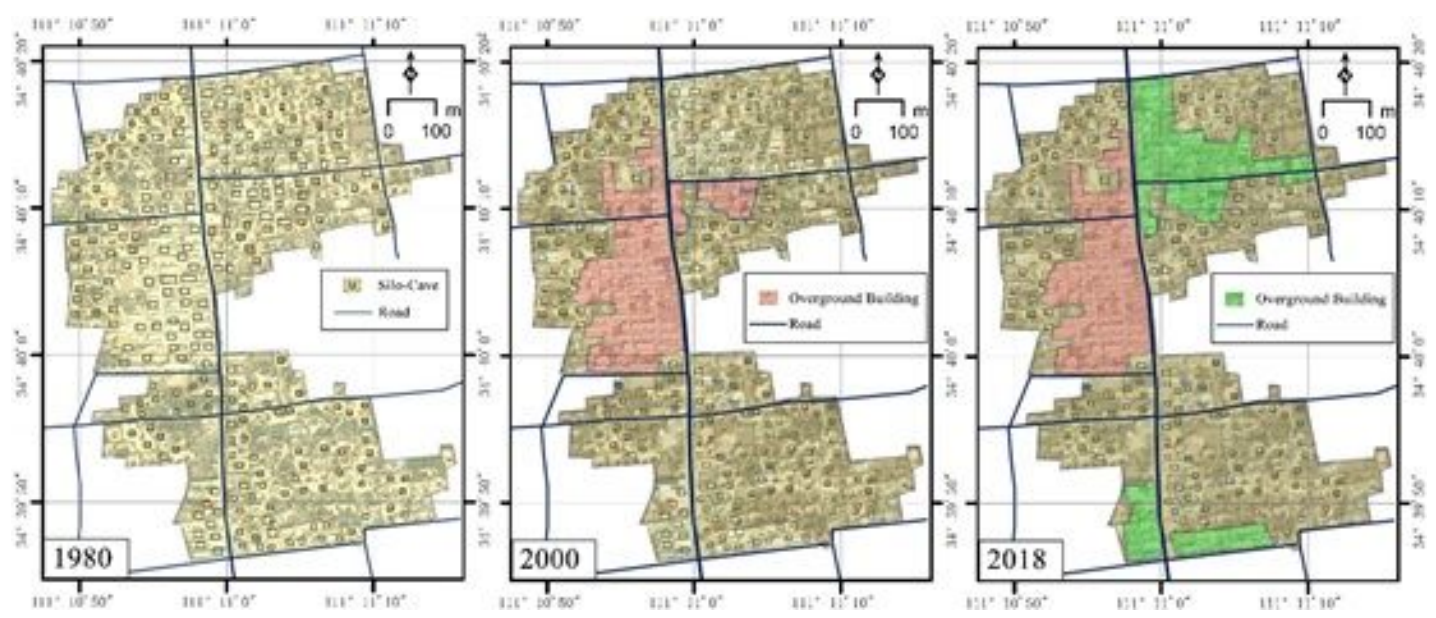

\section{Figure 5}

Evolution of Houguan Village, Xizhangcun Town, Shanzhou District, Henan, in 1978-2018. Note: The designations employed and the presentation of the material on this map do not imply the expression of any opinion whatsoever on the part of Research Square concerning the legal status of any country, territory, city or area or of its authorities, or concerning the delimitation of its frontiers or boundaries. This map has been provided by the authors.
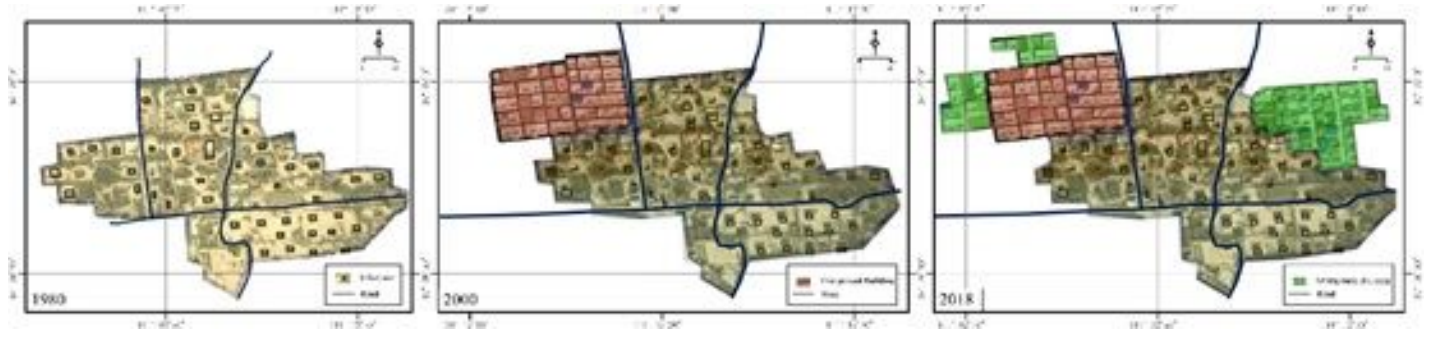

\section{Figure 6}

Morphological evolution of Miaoshang Village, Xizhangcun Town, Shanzhou District in 1980-2018. Note: The designations employed and the presentation of the material on this map do not imply the expression of any opinion whatsoever on the part of Research Square concerning the legal status of any country, territory, city or area or of its authorities, or concerning the delimitation of its frontiers or boundaries. This map has been provided by the authors.
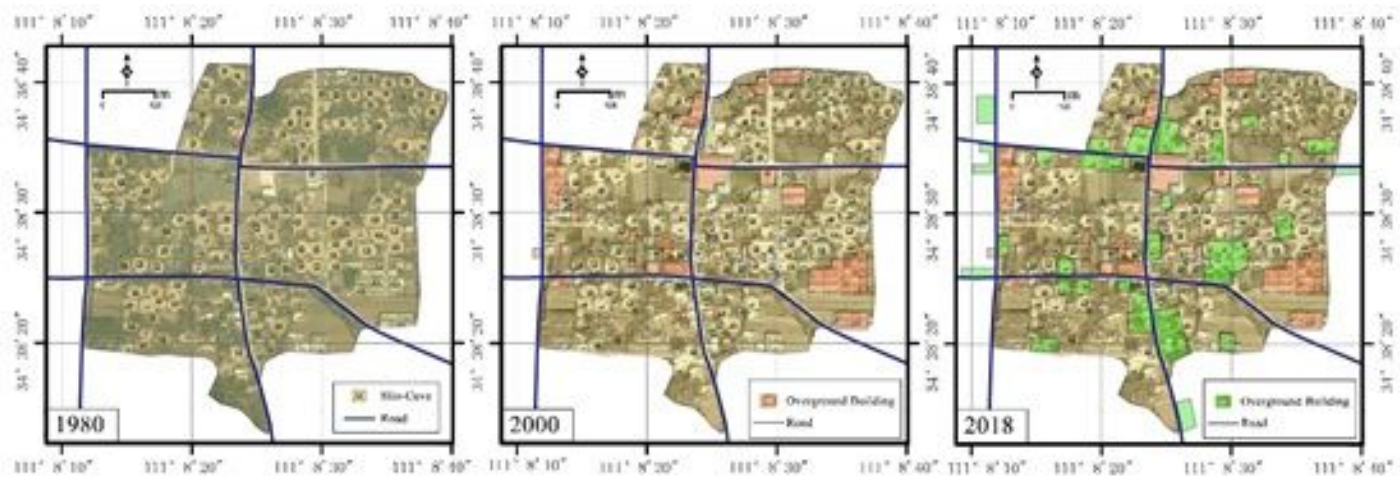

Figure 7 
Morphological evolution of Qucun Village, Zhangbian Town, Shanzhou District in 1980-2018. Note: The designations employed and the presentation of the material on this map do not imply the expression of any opinion whatsoever on the part of Research Square concerning the legal status of any country, territory, city or area or of its authorities, or concerning the delimitation of its frontiers or boundaries. This map has been provided by the authors.
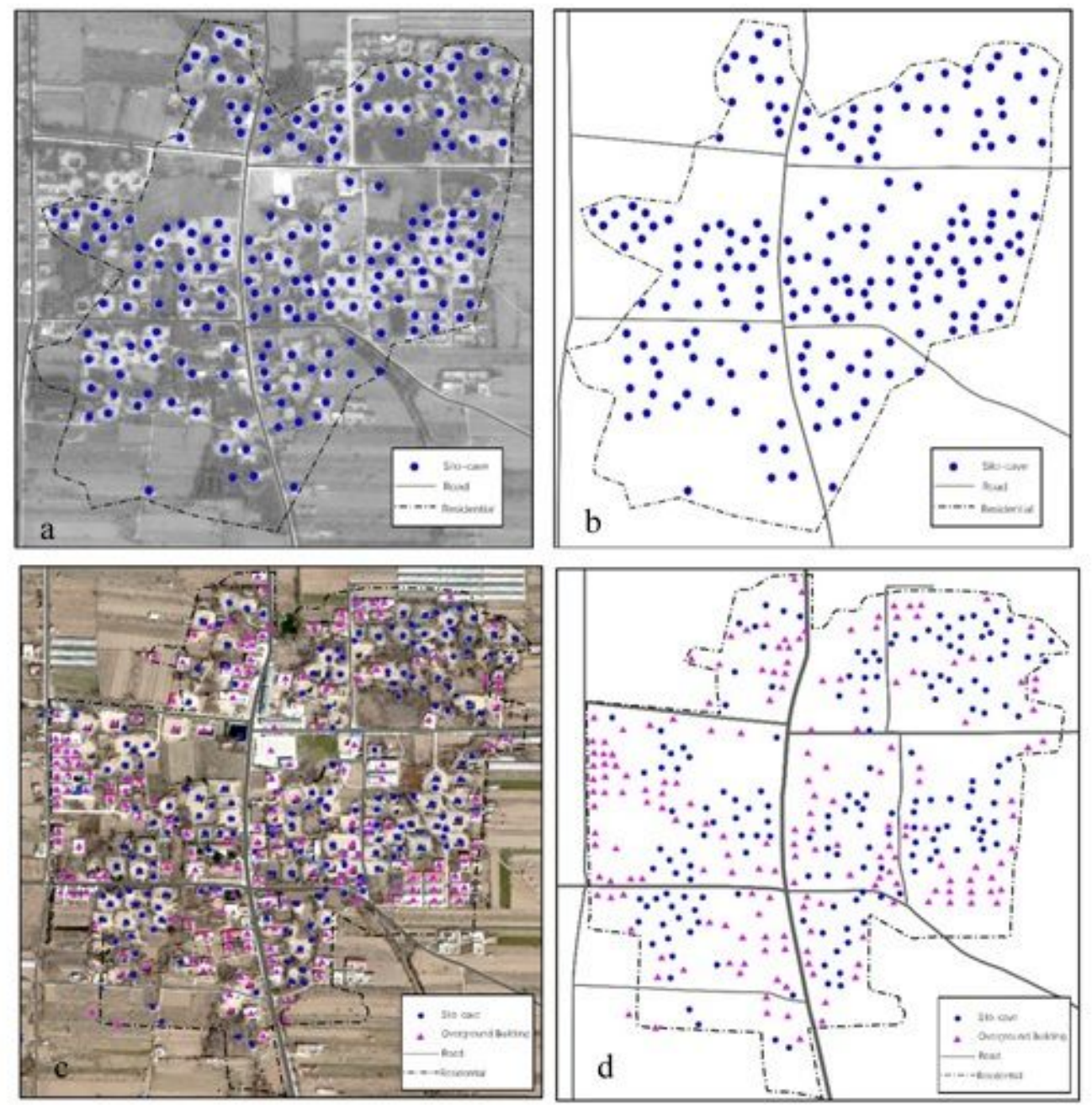

\section{Figure 8}

Remote sensing imaging and vector graph of the settlement distribution in Qucun in 1969 and 2018: (a)Remote sensing imaging of Qucun, 1969; (b) Remote sensing interpretation of Qucun, 1969; (c) Remote sensing imaging of Qucun, 2018; (d) Remote sensing interpretation of Qucun, 2018. Note: The designations employed and the presentation of the material on this map do not imply the expression of any opinion whatsoever on the part of Research Square concerning the legal status of any country, territory, city or area or of its authorities, or concerning the delimitation of its frontiers or boundaries. This map has been provided by the authors. 

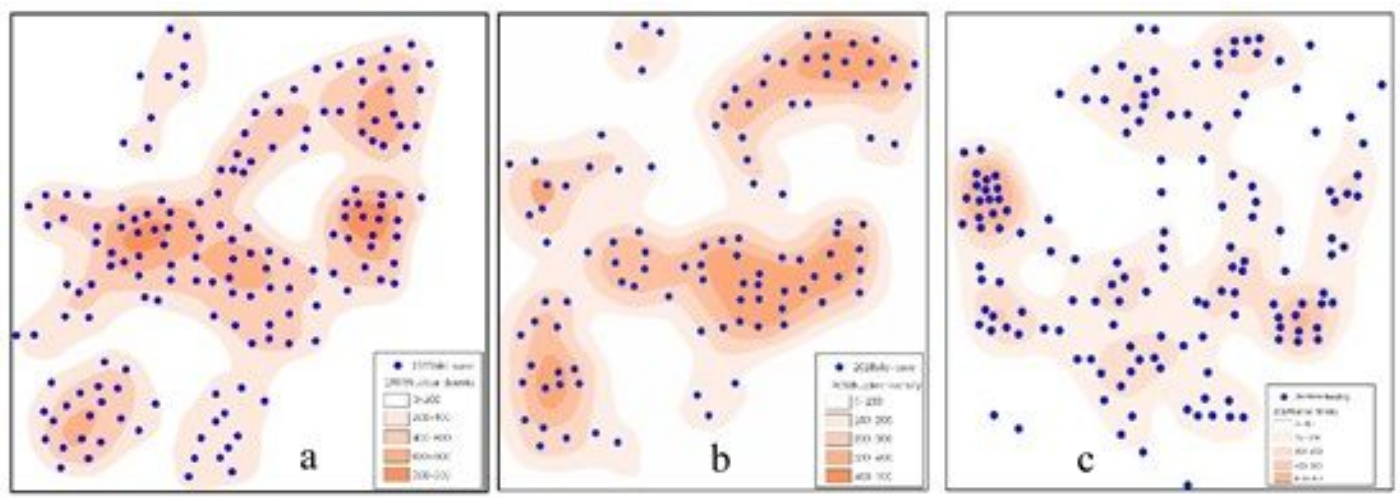

Figure 9

Kernel density spatial distribution of silo-caves in Qucun: (a) Silo-caves in 1969; (b)silo-caves in 2018;(c) above-ground buildings in 2018. Note: The designations employed and the presentation of the material on this map do not imply the expression of any opinion whatsoever on the part of Research Square concerning the legal status of any country, territory, city or area or of its authorities, or concerning the delimitation of its frontiers or boundaries. This map has been provided by the authors.
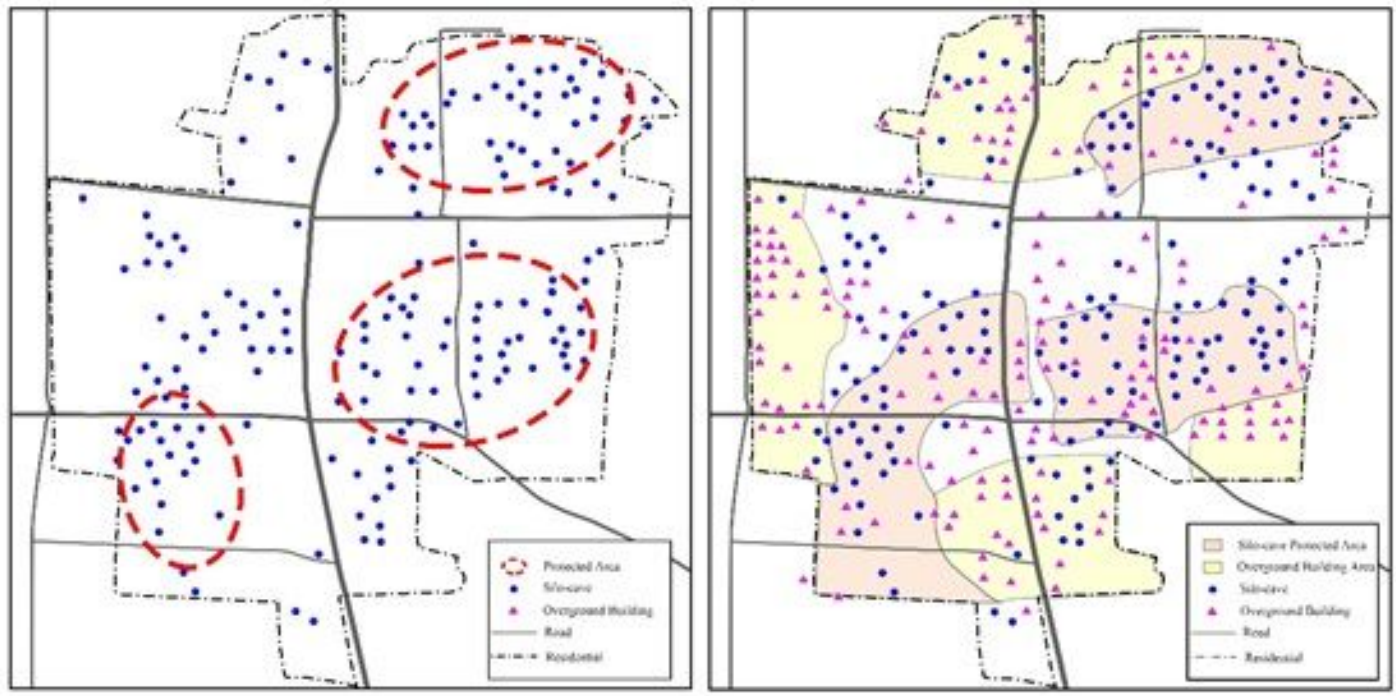

Figure 10

Modified internal structure of the traditional silo-cave village, Quncun: (a) Protection zones of silo-caves in Qucun;( b) Function division of the traditional silo-cave village, Qucun. Note: The designations employed and the presentation of the material on this map do not imply the expression of any opinion whatsoever on the part of Research Square concerning the legal status of any country, territory, city or area or of its authorities, or concerning the delimitation of its frontiers or boundaries. This map has been provided by the authors. 